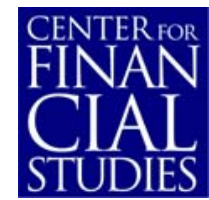

No. $2011 / 05$

Short Sale Constraints, Divergence of Opinion and Asset Values:

Evidence from the Laboratory

Gerlinde Fellner and Erik Theissen 


\section{Center for Financial Studies}

The Center for Financial Studies is a nonprofit research organization, supported by an association of more than 120 banks, insurance companies, industrial corporations and public institutions. Established in 1968 and closely affiliated with the University of Frankfurt, it provides a strong link between the financial community and academia.

The CFS Working Paper Series presents the result of scientific research on selected topics in the field of money, banking and finance. The authors were either participants in the Center's Research Fellow Program or members of one of the Center's Research Projects.

If you would like to know more about the Center for Financial Studies, please let us know of your interest.

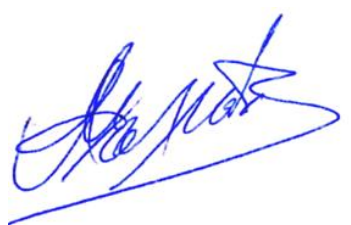

Prof. Michalis Haliassos, Ph.D.
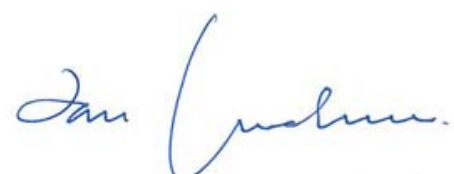

Prof. Dr. Jan Pieter Krahnen

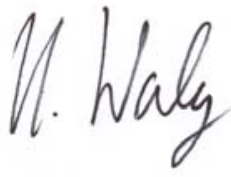

Prof. Dr. Uwe Walz 


\title{
Short Sale Constraints, Divergence of Opinion and Asset Values: Evidence from the Laboratory*
}

\author{
Gerlinde Fellner ${ }^{1}$ and Erik Theissen ${ }^{2}$
}

January 2011

\begin{abstract}
:
The overvaluation hypothesis (Miller 1977) predicts that a) stocks are overvalued in the presence of short selling restrictions and that $b$ ) the overvaluation increases in the degree of divergence of opinion. We design an experiment that allows us to test these predictions in the laboratory. The results indicate that prices are higher with short selling constraints, but the overvaluation does not increase in the degree of divergence of opinion. We further find that trading volume is lower and bid-ask spreads are higher when short sale restrictions are imposed.
\end{abstract}

JEL Classification: C92, G14

Keywords: Overvaluation Hypothesis, Short Selling Constraints, Divergence of Opinion

\footnotetext{
* We are grateful for the valuable comments given by Brian Kluger, Stefan Nagel and participants of the 33rd an-nual meeting of the European Finance Association and the 14th annual meeting of the German Finance Associa-tion. We are indebted to Rouhollah Mohammadi for his research assistance. We gratefully acknowledge the finan-cial support from Deutsche Forschungsgemeinschaft through SFB/TR 15.

1 University of Cologne, Department of Economics, Albertus-Magnus-Platz, 50931 Koeln, Germany, E-mail: Gerlinde.Fellner@uni-koeln.de

2 University of Mannheim, Centre for Financial Research (Cologne) and Center for Financial Studies (Frankfurt). Address correspondence to: Erik Theissen, University of Mannheim, Finance Area, L5, 2, 68131 Mannheim, Germany, E-mail: theissen@uni-mannheim.de, phone: +49 621 1811517. fax: +49 6211811519 .
} 


\section{$1 \quad$ Introduction}

If traders in financial markets have different opinions about the value of an asset, the optimists will buy and the pessimists will sell. Short sale restrictions prevent traders not currently owning an asset from selling it and thus exclude pessimistic traders from the market. The marginal traders' assessments of the asset value will thus be above average. If the price reflects these optimistic assessments, the asset will be overvalued, and the overvaluation will increase in the degree of divergence of opinion. This is the overvaluation hypothesis, which was first put forward by Miller (1977). Although it is incompatible with a rational expectations equilibrium (Diamond and Verrecchia 1987), it has received much attention (and a fair amount of empirical support) in the literature. The first wave of empirical studies dates from the 1980s and early 1990s; however, interest in the issue has been reignited recently, partially motivated by the question of whether short selling constraints contributed to the internet bubble of the late nineties. A third, and still ongoing, wave of research has been motivated by the short selling ban on financial stocks imposed by the SEC in September 2008.

The empirical results, summarized briefly in section 2, are inconclusive. A possible explanation for the contradictory findings is the fact that empirical research into the issue is complicated by a number of impediments. Most importantly, neither the value of a stock nor the degree to which it is short sale constrained is directly observable. The same applies to the degree of divergence of opinion. Consequently, researchers have to rely on proxies for all variables of interest. These proxies may be noisy or even biased, and they may be correlated with other stock characteristics that affect valuation. Therefore, a controlled laboratory experiment that stringently tests Miller's hypothesis can help to shed more light on the issue.

In spite of the apparent advantages of an experimental approach, we know of only four papers that vary the level of short selling constraints in the laboratory (King et al. 1993, Ackert et al. 2002, Haruvy and Noussair 2006, and Bhojraj et al. 2009). The designs of these experiments differ from ours in a number of important ways. Most importantly, there is no uncertainty about the fundamental value of the asset and, consequently, no divergence of opinion. Therefore, none of these papers can be considered as a direct test of Miller's (1977) overvaluation hypothesis. 
Our paper contributes to the literature by providing the first complete experimental test of the overvaluation hypothesis. None of the measurement problems alluded to above are present in the laboratory. The experimenter controls the information structure and, consequently, the degree of divergence of opinion. Similarly, short sale constraints are imposed by the experimenter. As identical assets van be traded with and without constraints, it is feasible to directly compare the market values of the assets, rather than inferring overvaluation from proxy variables or subsequent returns. The results of our experiments provide only partial support for the overvaluation hypothesis. Prices in the experimental markets are higher when short selling is prohibited. However, the overvaluation does not depend on the degree of divergence of opinion. We further find that trading volume is lower and bid-ask spreads are higher when short sale constraints are imposed. This is consistent with recent empirical evidence from the 2008 short selling ban (e.g. Beber and Pagano 2009, Boehmer et al. 2009).

The remainder of the paper is organized as follows. The next section presents a brief summary of the literature. We describe the experimental design and procedures in section 3 and the hypotheses in section 4 . Section 5 presents and discusses our results. In section 6 , we summarize our results and offer concluding remarks.

\section{$2 \quad$ Literature}

As noted in the introduction, the overvaluation hypothesis was first put forward by Miller (1977). The basic intuition is simple: if traders have different opinions about the value of an asset, the optimists will buy and the pessimists will sell. However, short sale constraints prevent those pessimists not currently owning the asset from selling it. Optimistic opinions will then be overrepresented in market prices. Consequently, short sale restrictions lead to overvaluation that increases in the degree of divergence of opinion.

The overvaluation hypothesis put forward by Miller (1977) is inconsistent with a rational expectations equilibrium. ${ }^{4}$ Diamond and Verrecchia (1987) presented a rational expectations model in which short sale constraints do not lead to overvaluation but reduce the speed at

4 It is fair to note that Miller (1977) was well aware of the limitations of his model. He explicitly refers to the winner's curse problem and argues (p. 1158) that "many investors are still following naive procedures". 
which new information, negative information in particular, is incorporated into prices. Similar results, though in a very different context, are derived in Hong and Stein (2003). Recent theoretical research has revived the overvaluation hypothesis. Duffie et al. (2002) derived a model in which short sale constraints together with divergence of opinion (modeled by assuming different priors about the payoff distribution) may lead to overvaluation. In the model by Johnson (2004), higher degrees of divergence of opinion lead to lower subsequent returns in a fully rational context. In Scheinkman and Wei (2003), overconfidence creates divergence of opinion and, in the presence of short sale constraints, may lead to overvaluation. A similar result is derived in Jiang (2005). Gallmeyer and Hollifield (2008) presented a model in which the imposition of short sale constraints can either increase or decrease stock prices, depending on the optimistic investors' intertemporal elasticity of substitution.

Researchers have used various approaches in order to empirically test the overvaluation hypothesis. The most common one is to consider a cross-section of stocks and to test whether stocks that are subject to short selling constraints are overvalued and whether overvaluation depends on the degree of divergence of opinion. This requires (a) the identification of stocks that are short sale constrained, (b) a measure of asset value to identify overvaluation and (c) a measure for the degree of divergence of opinion. ${ }^{5}$

Various measures have been employed to identify short sale constrained stocks. These include considering the short interest (Figlewski and Webb 1993, Asquith and Meulbroek 1996, Dechow et al. 2001, Desai et al. 2002, Asquith et al. 2005, Boehme et al. 2006, Cohen et al. 2005), institutional ownership (Asquith et al. 2005, Nagel 2005, Berkman et al. 2009), the availability of options on the stock (Figlewski and Webb 1993, Danielsen and Sorescu 2001, Mayhew and Mihov 2004, Boehme et al. 2006, Phillips 2011), the inclusion of a stock in the "threshold list" (Diether et al. 2005), the rebate rate (Jones and Lamont 2002, Reed 2007, Ofek et al. 2004, Boehme et al. 2006, Cohen et al. 2005) and failures to deliver (Autore et al. 2010b, Diether and Werner 2010). However, recent evidence on the amount of short selling (12.9\% of NYSE volume in the period 2000 to 2004 as reported in Boehmer et al. 2008; 24\% of NYSE

\footnotetext{
5 Some papers have used alternative approaches to test Miller's hypothesis. Dong and Michel (2008) found that IPO undervaluation is increasing in measures of the heterogeneity of investor beliefs. Greenwood (2009) reported that trading restrictions around stock splits in Japan result in overvaluation.
} 
volume and even $31 \%$ of Nasdaq volume in 2005 as documented by Diether et al. 2009a) suggests that short selling constraints are not very widespread in the U.S. stock market.

Some researchers identify overvalued stocks by analyzing valuation ratios (Dechow et al. 2001, Desai et al. 2002, Jones and Lamont 2002), by considering adjustments to analysts' earnings forecasts (Francis et al. 2005) or by considering firm age or earnings volatility (Berkman et al. 2009). The most widespread approach is to rely on subsequent returns to identify overvalued stocks. This approach is based on the implicit assumption that either short sale constraints are removed or the divergence of opinion is reduced (e.g., because new information is released), leading to a decrease in the level of overvaluation. Negative returns are thus taken as evidence of initial overvaluation.

The most widely used proxy for the degree of divergence of opinion is the standard deviation of analyst forecasts (Diether et al. 2002, Boehme et al. 2006, Berkman et al. 2009), but the standard deviation of returns and the turnover ratio have also been employed (Berkman et al. 2009, Boehme et al. 2006).

In summary, none of the variables of interest can easily be measured. In addition, the two explanatory variables - the degree to which a stock is short sale constrained and the degree of divergence of opinion - may not be independent. D'Avolio (2002) documented that a stock is more likely to be "on special" (i.e., to be expensive to sell short) when the degree of divergence of opinion is high.

Given the measurement problems and the different approaches implemented to resolve them, it is not surprising that the results in the empirical literature are not unanimous. A majority of papers find results that are supportive of the overvaluation hypotheses (e.g., Figlewski and Webb 1993, Danielsen and Sorescu 2001, Dechow et al. 2001, Desai et al. 2002, Diether et al. 2002, Jones and Lamont 2002, Gopalan 2003, Ofek et al. 2004, Boehme et al. 2006, Cohen et al. 2005, Nagel 2005, Berkman et al. 2009, Aitken et al. 1998, Chang and Yu 2007 and Berkman and Koch 2008). Aitken et al. (1998) made use of the fact that in Australia, short sales are transparent. Using intraday event study methodology, they found that prices almost instantaneously decrease after a short sale. Chang and Yu (2007) used data from Hong Kong, where only stocks that are included on a short sale list can be shorted. The list is revised from time to time. Additions to and deletions from the list are associated with abnormal returns, the sign of which is consistent with the overvaluation hypothesis. Berkman and Koch (2008) analyzed trading activity prior to earnings announcements. They found that trading in the wake of earn- 
ings announcements is dominated by buyer-initiated trades and that there are price run-ups particularly for stocks characterized by low institutional ownership (which are difficult to sell short) and high degrees of divergence of opinion.

Other papers support the overvaluation hypothesis only partially, e.g., when equallyweighted portfolios are considered (Asquith et al. 2005). Diether et al. (2005) found that returns of small stocks are negative after a period of increased short selling (which is consistent with the overvaluation hypothesis) but that returns after inclusion of small firms in the threshold list are, if anything, negative. The latter result is inconsistent with the overvaluation hypothesis because inclusion in the threshold list implies more binding short sale restrictions. Brent et al. (1990) reported that returns are not smaller in the month after an increase in short interest, which is also inconsistent with the overvaluation hypothesis. Mayhew and Mihov (2004) presented evidence suggesting that the negative returns around option listings documented by others are not robust. They conclude by stating (p. 22) that "we now believe that there is no credible evidence from option markets that a marginal change in the cost of short selling can have an impact on prices." Boehmer et al. (2010) found that there is no asymmetry between the speeds at which positive and negative information are impounded into prices. ${ }^{6}$ This is inconsistent with the overvaluation hypothesis and leads the authors to conclude that "[o]ur results ... cast doubt on existing theories of the impact of short sale constraints."

Kaplan et al. (2010) conducted an interesting field experiment. They worked with a large asset manager who randomly withheld some of the stocks in his portfolio from the lending market. This creates exogenous variation in short sale restrictions which, according to the overvaluation hypothesis, should affect prices. However, Kaplan et al. (2010) did not find evidence of a significant impact on prices. In a recent paper, Diether et al. (2009b) analyzed whether the suspension of the short sale price tests mandated by the SEC (regulation SHO) affected stock returns. Because the price tests deter short selling, the overvaluation hypothesis predicts negative returns. However, the evidence is inconsistent with that prediction. In an analysis of the internet bubble Battalio and Schultz (2006) found no evidence that short sale constraints affected the prices of Internet stocks. Finally, several papers test whether the short

6 Au et al. (2009) arrived at a similar conclusion. They find that idiosyncratic volatility (which affects both short and long positions) is a more important deterrent to short selling than short sale costs. 
sale ban imposed by the SEC in September 2008 led to an increase in the prices of the stocks that were subjected to the ban, and Autore et al. (2010a), Boulton and Braga-Alves (2010), Gagnon and Witmer (2010) and Harris et al. (2009) found supporting evidence for an increase. However, obtaining clear results is difficult because the Troubled Assets Relief Program and other programs were announced on the same day. From an analysis of stocks that were later added to the ban list, Boehmer et al. (2009) concluded that "the ban may not have provided much of an artificial price boost."

Conflicting findings are provided by Bris et al. (2007) and Charoenrook and Daouk (2005). Both compared stock return characteristics in countries with and without short sale restrictions. The papers conclude that allowing short sales increases the efficiency of price discovery. Charoenrook and Daouk (2005) found that when countries start to allow short selling, aggregate stock returns increase. This is clearly inconsistent with the overvaluation hypothesis. $^{7}$

In summary, even though a number of empirical papers find results supportive of the overvaluation hypothesis, it appears fair to conclude that the issue is not yet settled. The measurement issues alluded to above suggest that an experimental approach is called for. We are aware of four papers that addressed the effect of short sale constraints on pricing in a laboratory setting. Three of these papers (King et al. 1993, Ackert et al. 2002 and Haruvy and Noussair 2006) build on the experiments of Smith, Suchanek and Williams (1988). These authors found evidence of persistent and frequent price bubbles in experimental markets for a long-lived asset with short sale constraints in place. King et al. 1993, Ackert et al. 2002 and Haruvy and Noussair 2006 tested whether lifting the short selling constraints reduced the frequency and / or the magnitude of the bubbles. The results were mixed. King et al. (1993) found that a relaxation of the short sale constraints did not have much impact on the occurrence of bubbles. Ackert et al. (2002), on the other hand, found prices closer to the fundamental value of the asset when the short sale restrictions were relaxed. Haruvy and Noussair (2006) used a more differentiated experimental design and found that removing short sale restrictions reduced prices, but does not necessarily make them more efficient. In fact, when short sales were allowed, prices may

\footnotetext{
7 Charoenrook and Daouk (2005) attributed their result to increased liquidity, which, in turn, lowers expected returns and thus leads to an increase in stock prices.
} 
be significantly below the fundamental value. A common feature of these experiments is that traders received symmetric information about the asset value. There is thus no divergence of opinion. ${ }^{8}$ Consequently, none of these papers can be considered a test of Miller's (1977) overvaluation hypothesis because it states that the divergence of opinion is a necessary condition for overvaluation to occur.

Bhojraj et al. (2009) ran a series of experiments in which they varied margin requirements. This is similar to varying the degree of short sale constraints. The fundamental value of the asset in their experiments was fixed and known to all traders. Thus, there was again no uncertainty (and, consequently, no divergence of opinion) about fundamentals. The price was a deterministic function of the excess demand. A robot (the "sentiment trader") bought assets in each period, thus putting upward pressure on the prices. If there were no short selling constraints, the traders should drive down the price to the fundamental value. If restrictions were in place, the equilibrium price may be above the fundamental value. The results indicate that relaxing margin requirements (and thereby short sale constraints) can even exacerbate overpricing, which is at odds with the overvaluation hypothesis. The experiments of Bhojraj et al. (2009) were designed to address how margin requirements and, in particular, the risk of margin calls affect pricing efficiency. Given that a) there is no fundamental uncertainty and b) the presence of the sentiment trader drove equilibrium prices above fundamentals when short selling constraints are binding, their experiments were not (and from our reading, not intended to be) a direct test of the overvaluation hypothesis.

\section{Experimental Design and Procedures}

Our experimental design differs in a number of important ways from former experiments. Most importantly, in all previous experiments, subjects had symmetric information. Obviously, the degree of divergence of opinion cannot be varied in a symmetric information setting. Another important difference is that the experiments in three of the four previous stu-

\footnotetext{
8 There may be differences of opinion due to strategic uncertainty, i.e., uncertainty with respect to the behaviour of other subjects. Strategic uncertainty is, however, not under the control of the experimenter.
} 
$\operatorname{dies}^{9}$ featured a long-lived asset with a fundamental value that declined through the course of the experiment. Endowments were not re-initialized. Consequently, a subject exhausting her short selling capacity in one period was unable to sell in the next period. In contrast, our experiments consisted of stationary replications of a one-period economy.

We conducted 18 experimental sessions in which a total of 180 subjects participated. ${ }^{10}$ Participants were recruited among economics students at the University of Bonn using the online recruiting system ORSEE (Greiner 2004). Ten subjects were assigned to one cohort. Each cohort participated in one experimental session that consists of three distinct parts. To allow the subjects to get acquainted with the computerized trading system, the sessions started with three training periods that have been excluded from the analysis. Subsequently, there were 20 trading periods. In 10 of these periods, short selling was prohibited, and in ten periods, it was allowed. We thus chose a within-subjects design, i.e., each cohort faces both the short selling condition and the no short selling condition. To control for order effects, half of the cohorts encountered the short selling condition first, and the other half faced the no short selling condition first.

Subjects received a $20 €$ show-up fee for participation. In addition, at the end of the session, two periods (one period of the no short selling condition and one period of the short selling condition) were determined randomly. The profit of these periods were converted into Euros at a rate of $20 \mathrm{ECU}^{11}=1 €$ and added to (or subtracted from) the show-up fee.

\footnotetext{
9 The exception is Bhojraj et al. 2009.

10 Four sessions were conducted with experienced subjects. We thus had 100 subjects who participated in one session and 40 subjects who participated in two sessions. Double-counting the latter group yields the number of 180 participants.

11 In the experiment, all prices are denoted in Experimental Currency Units (ECU).
} 


\section{$\underline{\text { Asset value and private signals }}$}

Subjects in the experiments traded a risky asset against a numéraire (cash, denoted Experimental Currency Units, ECU). The value of the asset was a random variable denoted $\tilde{V}$. The value was high $(\mathrm{H})$ or low $(\mathrm{L})$ with equal probabilities. The realization was determined randomly at the beginning of each period but was only revealed after the end of the period. Draws in different periods were independent of each other.

At the beginning of the period, each subject received a private signal $s$ that provided information on the value of the asset. The signal was either $h$ (indicating a high value) or $l$ (indicating a low value). The signal had precision $p$ where $p$ was the probability that the signal is correct, i.e.,

$$
p=\operatorname{Prob}(h \mid H)=\operatorname{Prob}(l \mid L)
$$

The signal is uninformative if $\mathrm{p}=0.5$, it is informative but noisy if $0.5<\mathrm{p}<1$ and it is perfectly accurate if $p=1$. The conditional expectation of the asset value was

$$
\begin{aligned}
& E(\tilde{V} \mid s=h)=p H+(1-p) L=L+p(H-L) \\
& E(\tilde{V} \mid s=l)=p L+(1-p) H=H-p(H-L)
\end{aligned}
$$

\section{Divergence of opinion}

We wished to test the hypothesis that the overvaluation implied by the existence of short sale constraints increases in the degree of divergence of opinion among traders. We therefore varied the degree of divergence of opinion across (but not within) cohorts.

Our measure for the degree of divergence of opinion was the cross-sectional variance of the conditional expected value of the asset. If the asset value was high $(\mathrm{H})$, on average a frac- 
tion $p$ of the traders received the signal $h$ and a fraction $(1-p)$ received the signal $l$. The mean of the conditional expectations was then

$$
\begin{aligned}
E[E(\tilde{V} \mid s) \mid \tilde{V}=H] & =p[L+p(H-L)]+(1-p)[H-p(H-L)] \\
& =H-2 p(1-p)(H-L)
\end{aligned}
$$

The cross-sectional variance of the conditional expected value of the asset was then

$$
\begin{aligned}
\operatorname{Var}[E(\tilde{V} \mid s) \mid \tilde{V}=H] & =p\{[L+p(H-L)]-[H-2 p(1-p)(H-L)]\}^{2} \\
& +(1-p)\{[H-p(H-L)]-[H-2 p(1-p)(H-L)]\}^{2} \\
& =p(1-p)\left(4 p^{2}-4 p+1\right)(H-L)^{2}
\end{aligned}
$$

The corresponding values for the case of a low asset value were

$$
\begin{aligned}
E[E(\tilde{V} \mid s) \mid \tilde{V}=L] & =(1-p)[L+p(H-L)]+p[H-p(H-L)] \\
& =L+2 p(1-p)(H-L)
\end{aligned}
$$

and

$$
\operatorname{Var}[E(\tilde{V} \mid s) \mid \tilde{V}=L]=p(1-p)\left(4 p^{2}-4 p+1\right)(H-L)^{2}
$$

Thus, irrespective of the realization of the asset value, ${ }^{12}$ the cross-sectional variance of the conditional expectations of the asset value was proportional to $\theta \equiv p(1-p)\left(4 p^{2}-4 p+1\right)$. Therefore, we used $\theta$ to measure the degree of divergence of opinion. $\theta$ is zero when $p=0.5$, because in this case, the signals are uninformative and the conditional expectations of the asset value are equal to the unconditional expectation. $\theta$ increases when the signal becomes informative. $\theta$ approaches zero when the signal precision $p$ goes to one. This is the case because

\footnotetext{
12 This is an implication of our assumption that the asset value is equally likely to be high or low.
} 
the number of traders who receive a wrong signal goes to zero when $p$ approaches 1 . There exists a signal precision $p$ that maximizes the degree of divergence of opinion. This maximum value is obtained for $p$ equal to 0.85 . Figure 1 graphs $\theta$ as a function of $p$.

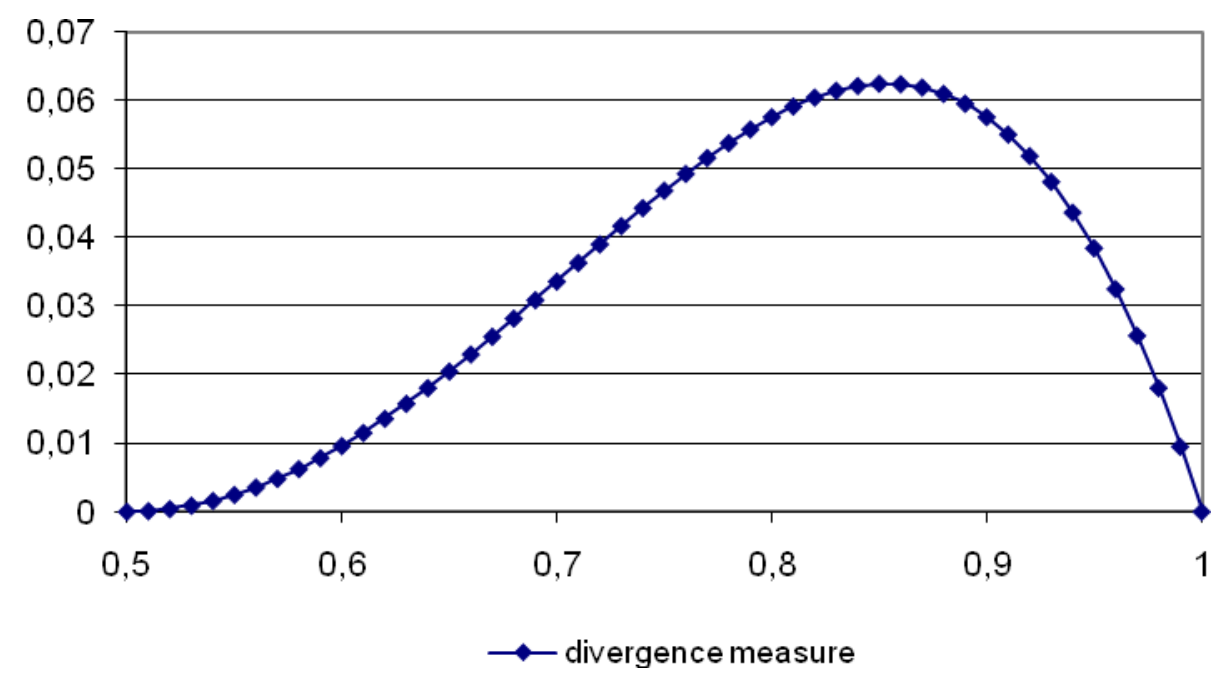

Figure 1: Divergence measure $\theta$ against the signal precision $p$

\section{Parameter choice}

We chose the following parameters: $\mathrm{H}$ was set equal to 200, and $\mathrm{L}$ was set equal to 100 . To vary divergence of opinion, we chose two different signal precisions. In some sessions, $\mathrm{p}$ equaled 0.6 , and in other sessions, $\mathrm{p}$ was equal to 0.8 . The two treatments were characterized by very different degrees of divergence of opinion. Table 1 shows the expectation of the asset value conditional on the realization of the signal and its precision. It further presents the expected number of traders with correct and incorrect signals and the measure $\theta$ for the degree of divergence of opinion.

Insert Table 1 about here 
Previous experimental studies featuring a long-lived asset (e.g., Smith et al. 1988, King et al. 1993, Ackert et al. 2002 and Haruvy and Noussair 2006) have documented that without a short selling possibility, overvaluation may arise even in the absence of asymmetric information. It is not clear whether this result extends to our design because we analyzed static repetitions of a one-period economy rather than a long-lived asset. Still, to test whether the same effect arose in our experiments, we conducted two sessions with symmetric information. In these sessions, subjects did not receive private signals. We used the results of these sessions as a benchmark to measure the impact of divergence of opinion.

\section{Endowments and short selling restrictions}

Subjects in each session were randomly and independently subdivided into two endowment groups at the beginning of each period. The different endowments created a rational motive for trade among subjects. Half of the subjects were endowed with four assets and 150 ECU (denoted the share endowment group). The remaining subjects were endowed with one asset and 600 ECU (denoted the cash endowment group). The (unconditional) expected values of the endowments were equal. Subjects of both endowment groups had unlimited access to credit at a zero interest rate. Therefore, a situation where a subject would have liked to buy assets but was unable to do so could not arise.

In the no short selling treatment, short sales were prohibited. The trading system rejected any offer that, if executed, would result in a short position. However, in the short selling 
treatment, short sales were allowed without any limitations and costs (e.g., lending fees). ${ }^{13}$ Short positions were covered at the end of the trading period. For each share shorted, an amount equal to the true value of the asset was deducted from the subject's cash balance.

At the end of each period, the terminal wealth of each subject was calculated by adding the end-of-period cash balance and the value of the share portfolio (the product of the number of shares and their fundamental value). The profit was then calculated as the difference between the end-of-period wealth and the value of the endowment. ${ }^{14}$

\section{Market structure}

The market was a computerized continuous auction market with an open limit order book. We used the software zTree (Fischbacher 2007) to implement the trading system at the University of Bonn Experimental Economics Laboratory (BonnEconLab).

Each trading period lasted 150 seconds. At the beginning of each trading period, the limit order book was empty. Traders could submit limit orders or accept standing limit orders submitted by others. Order execution was governed by price and time priority. Order size was restricted to one share. The minimum tick size was set to one ECU which amounts to $0.67 \%$ of the unconditional expected value of the asset.

Trading was anonymous; subject identification codes were thus not visible on the screen. There was full post-trade transparency, i.e., transaction prices (but not the identity of

\footnotetext{
13 This implies that shorting supply is infinite. Alternatively, we could allow short selling but restrict the amount of shares that can be shorted, or we could introduce short selling costs. Results in Cohen et al. (2007) suggest that it is shorting demand, rather than supply, that causes valuation effects. We therefore decided to (implicitly) vary the shorting demand by imposing different degrees of divergence of opinion, but to keep shorting supply constant.

14 The share endowment was valued at the fundamental value of the shares. Thus, a subject who did not trade had a profit of zero irrespective of the realization of the asset value.
} 
the traders) were visible to all traders. Subjects were not able to identify whether a trade they observed results in a short position.

\section{Implementation issues}

If the realizations of the signals were determined entirely randomly, we would face two (related) problems. First, because the number of traders with correct and incorrect signals was determined randomly and thus changes, the effective degree of divergence of opinion may differ from the value shown in Table 1 and change across periods. Second, it may happen (particularly in the $\mathrm{p}=0.8$ treatment) that no trader obtains a wrong signal. In that case, however, there would be no informational asymmetry (although subjects would not be aware of that fact).

To avoid these problems, we chose a modified procedure by fixing the number of correct and incorrect signals at their expected values. In the $p=0.6[0.8]$ treatments, always six [eight] traders received a correct signal and four [two] traders received an incorrect signal. Additionally, symmetry across the two endowment groups was imposed. Thus, in both endowment groups of the $\mathrm{p}=0.6[0.8]$ treatment, there were three [four] traders with a correct signal and two traders [one trader] with an incorrect signal.

This procedure had the advantage that, from the point of view of the individual subject, signals were still determined randomly with known precision $\mathrm{p}=0.6[0.8]$, while at the same time, the value of $\theta$ was held constant.

It may be the case that, with experience, subjects learn to avoid overvaluation. In principle, this issue can be addressed by comparing misvaluation across periods and by comparing the results of those treatments where the sequence of short selling and no short selling is reversed. However, the 20 periods of an individual experiment may have not been sufficient for 
learning to occur. To account for this possibility, we additionally conducted four sessions with experienced subjects, i.e., subjects that had already participated in a previous experimental session.

Table 2 summarizes the treatments and introduces the notation that will be used in the sequel. "E" denotes a session with experienced subjects.

Insert Table 2 about here

\section{$4 \quad$ Hypotheses}

Binding short sale constraints prevent traders who are willing to sell from doing so and will thus lead to lower trading volume. We therefore expect lower trading volume when short sale restrictions are in place. Trading volume, in turn, is known to affect liquidity. We therefore also expect that liquidity is lower when short sale constraints are imposed. This hypothesis is supported by empirical evidence from the 2008 short sale ban. Both Beber and Pagano (2009) and Boehmer et al. (2009) found that the ban adversely affected liquidity. We measured liquidity by the quoted and effective bid-ask spreads in the experimental markets. We thus state

\section{Hypothesis 1: Trading volume and liquidity}

H1a: Trading volume is lower under short sale constraints

H1b: Bid-ask spreads are higher under short sale constraints

In the benchmark treatment (AP0 and PA0), traders only received information about the unconditional expected value of the asset. We should thus expect prices to be equal to or (because of risk aversion) lower than 150 . According to the overvaluation hypothesis, both short sale constraints and divergence of opinion are necessary conditions for overvaluation to occur. 
As there is no divergence of opinion in the benchmark treatment, we do not expect short sale restrictions to affect valuation. We thus expect

\section{Hypothesis 2: The benchmark treatment}

H2a: In the benchmark treatment, prices are equal to or (because of risk aversion) slightly lower than 150 .

$\mathrm{H} 2 \mathrm{~b}$ : In the benchmark treatment, there are no differences between the short-selling and the no short-selling conditions.

In those treatments with informational asymmetries (PA60, AP60, PA80 and AP80), there is divergence of opinion. The overvaluation hypothesis thus predicts that prices will be higher when short selling is prohibited. This yields

\section{Hypothesis 3: Short selling}

H3: In the presence of asymmetric information, prices are higher when short selling is prohibited.

The overvaluation hypothesis predicts that prices increase in the degree of divergence of opinion. In the experiment, we vary the degree of divergence of opinion, yielding

\section{Hypothesis 4: Divergence of opinion}

H4: The overvaluation due to short sale constraints is more pronounced when the degree of divergence of opinion is higher.

As noted previously, the overvaluation hypothesis in its original form is inconsistent with a rational expectations equilibrium. A similar statement can be made for our experimental design. If all subjects behave rationally, there will be no overvaluation. Even if subjects are not fully rational, they may learn and thus achieve outcomes closer to a rational expectations equi- 
librium in later periods. If learning occurs, we should also expect overvaluation to be less pronounced in those sessions that use experienced subjects. This leads to

\section{Hypothesis 5: Learning}

H5a: The amount of overvaluation decreases in the course of the experiment.

H5b: The amount of overvaluation is smaller in the sessions that use experienced subjects.

\section{$5 \quad$ Results}

\subsection{Trading Volume and Bid-Ask Spreads}

Before reporting the results of our hypothesis tests, we present descriptive statistics on trading activity in general and short selling activity in particular. Table 3 reports the total number of sales and the number of short sales. Two findings emerge. First, short sales account for a sizeable fraction of total trading activity. Aggregated over all treatments $31.3 \%$ of all sales are short sales. ${ }^{15}$ Incidentally, this number is very similar to the $31 \%$ reported for NASDAQ by Diether et al. (2009a). Second, both total trading volume and the number of short sales are considerably higher in the treatments with divergence of opinion.

\section{Insert Table 3 about here}

We now turn to a test of hypotheses $1 \mathrm{a}$ and $1 \mathrm{~b}$. Table 4 shows figures on trading volume. We report the mean and the median trading volume per period for the short selling and the no short selling conditions. Besides separate results for each treatment, the table also con-

\footnotetext{
15 To no surprise, traders with low signals engaged in significantly more short selling than traders with high signals.
} 
tains (in the last line) the results pooled over all treatments. These aggregate results clearly confirm Hypothesis 1a. Both the mean and the median trading volume were higher when short sales were allowed. The disaggregated data reveal a similar picture, although with exceptions. Trading volume was significantly higher when short sales were allowed in three out of six treatments. In the PA80 treatment, the mean was significantly higher whereas there was no significant difference in the median. In the remaining two treatments (PA0 and PA60), there was no significant difference in trading volume. In summary, the results indicate that trading volume tended to be higher when short selling was allowed.

\section{$\underline{\text { Insert Table } 4 \text { about here }}$}

Table 5 shows the results on bid ask spreads. We used two spread measures, the mean quoted spread (Panel A) and the mean effective spread (Panel B). We also calculated percentage spreads. The results were very similar and are therefore omitted. The results are broken down by the degree of divergence of opinion (benchmark, $p=0.6, p=0.8$ ) and by the order of treatments (P-A, A-P, pooled).

Consider first the columns labeled "pooled". They show results aggregated over the two treatment orders P-A and A-P. Consistent with hypothesis $1 \mathrm{~b}$, the mean quoted spread was always higher when short sales were prohibited. The difference is significant in the benchmark treatment and in the $\mathrm{p}=0.8$ treatment. The results for the mean effective spread are weaker. We found a significant difference in the predicted direction only in the benchmark treatment. In the other two treatments $(p=0.6$ and $p=0.8)$, we did not find significant differences.

Considering the results for the two treatment orders (P-A and A-P) separately reveals a slightly more differentiated picture. When the treatment order is P-A (short sales prohibited in the first half of the experiment and allowed in the second half), both quoted and effective 
spreads were always lower (and significantly so in 5 out of 6 cases) when short sales were allowed. However, when the treatment order is A-P, we found that (quoted and effective) spreads were lower when short sales were prohibited, which is at odds with our hypothesis. However, there is an intuitive explanation for this finding. The figures in the columns labeled P-A and A$\mathrm{P}$ reveal that there appears to be a pronounced treatment order effect. Consider the first two numbers in the first line of Panel A (benchmark case, short sales allowed). When the short sales treatment was the first treatment (A-P), the average quoted spread is 17.62 . When it was the second treatment (P-A), the average quoted spread is only 5.90. This pattern is found in five out of six cases (the exception being the no short sales treatment with high divergence of opinion). It thus appears that spreads generally declined in the course of the experiments.

\section{$\underline{\text { Insert Table } 5 \text { about here }}$}

Against this background, it is more appropriate to compare the spreads across short selling conditions for the first and the second half of the experiments separately, i.e., to compare the spreads in the short sales treatment in the P-A condition (where the short sales treatment is the second treatment) to the spreads in the no short sales treatment in the A-P condition (where the no short sales treatment is the second treatment) and similarly the spreads in the short sales treatment in the A-P condition to those in the no short sales treatment in the P-A condition. The resulting t-statistics are shown in the last two columns of Table 5. Out of a total of twelve cases (two spread measures, three divergence-of-opinion treatments and two treatment order conditions), spreads were significantly higher when short sales were prohibited in six cases. We therefore conclude that our results support the hypothesis that short sale constraints adversely affect liquidity as measured by quoted and effective spreads. This result is consistent with empirical results in recent papers studying the 2008 short selling ban (Beber and Pagano 2009, Boehmer at al. 2009). 


\subsection{Price Level}

Hypotheses 2 - 5 make predictions about the asset prices in different treatment conditions. A test of these hypotheses requires a summary statistic of the asset prices. We used three such measures. The first is simply the mean price for each period. This measure assigns equal weight to each transaction within a given period. As the prices early in a period are less informative, it may be preferable to use a weighting scheme that puts more weight on transactions occurring later in a period. We therefore used a digitally weighted average price as our second measure. It is defined as

$$
p_{j}^{d i g}=\frac{\sum_{i=1}^{T_{j}} i p_{i}}{\sum_{k=1}^{T_{j}} \sum_{i=1}^{j} i}
$$

where $T_{j}$ is the number of transactions in period $j$ and $p_{i}$ is the price of transaction $i$ in period $j$. If there are five transactions in a period, the first one receives weight $1 /(1+2+3+4+5)=1 / 15$, the second receives weight $2 / 15$ and so on. Our third measure was the mean of the bid-ask midpoints. The midpoint is not affected by the bid-ask spread and is therefore often considered to be a less noisy measure of asset value.

Hypothesis 2 relates to the benchmark treatment and predicts that prices in the benchmark treatment will be equal to or smaller than 150 (the unconditional expected value of the asset) and that, because of the absence of divergence of opinion, prices will not be higher when short selling is prohibited. We tested this hypothesis by analyzing the three price measures 
described above. We treated the observations from different periods as independent. ${ }^{16}$ We provide aggregate results and separated results for the PA and the AP treatments because the sequence in which the subjects faced the short selling and the no short selling treatment may have had an impact on market outcomes. In the benchmark treatment, we do not have to differentiate with respect to the realization of the asset value because subjects did not receive information about the value and, consequently, could not condition their actions on the asset value.

The results are shown in the first lines of the three panels of Table 6. Panel A shows the results for the equally weighted mean price, Panel B those based on the digitally weighted mean and Panel $\mathrm{C}$ those based on the bid-ask midpoint. All three measures yielded very similar conclusions. The only noteworthy difference is the observation that significance levels tended to be higher when the analysis is based on bid-ask midpoints. This corroborates our conjecture that the midpoint is a less noisy measure of asset value.

All three measures clearly indicate that prices for the benchmark treatments were significantly below 150 as shown in the first line of Table 6 . We therefore conclude that our experimental design does not produce the "bubbles" that provided the starting point of previous experiments on short sales (King et al. 1993, Ackert et al. 2002 and Haruvy and Noussair 2006).

Prices in the benchmark treatments were, however, significantly higher when short sales were prohibited (133.33 compared to 127.95 with a t-statistic of 2.17 , these figures are taken from Panel A). The disaggregated data show that this is mainly due to a large difference

\footnotetext{
16 This is a common practice. It should be noted, though, that data from different periods of the same session are not, strictly speaking, independent because the same subjects interact with each other and share a common history.
} 
in the PA treatment (129.67 when short sales were prohibited and 120.03 when they were allowed), whereas the difference in the AP treatment is insignificant. The other two measures of asset value yield identical conclusions. The results thus suggest that prices tend to be higher when short selling is prohibited even in the absence of divergence of opinion. This contradicts Hypothesis $2 b$.

\section{Insert Table 6 about here}

In the non-benchmark treatments, subjects received signals about the value of the asset. We should therefore expect prices to depend on the realization of the asset value process. Consequently, the results in Table 6 are presented conditional on the asset value being low (100) or high (200). In almost all cases, prices were higher when short sales were prohibited. There are only two exceptions from this general pattern (in the AP60 treatment and in the PA80 treatment, respectively, when the true asset value was high ${ }^{17}$ ).

Although the sign of the price difference generally conforms to our expectations, the significance of the results is modest. Only three (Panels A and B) or two (Panel C) out of twelve t-statistics indicate significance at the 5\% level (one-sided test). Taken together, these results provide weak support for our Hypothesis 3. They also suggest that, in contrast to Hypothesis 4 , the impact of short selling restrictions on prices is not increasing in the degree of divergence of opinion. A more formal test of Hypothesis 4 will be presented later.

Table 7 addresses the learning hypothesis. Because the three price measures yield very similar conclusions, we restrict the presentation to the equally weighted mean price. In Panel A of Table 7, we report separate results for the first half (periods 1-5) and the second half (pe-

17 In Panel $\mathrm{C}$ there is a third exception in the "all" column for $\mathrm{p}=0.8$ and a high asset value. 
riods 6-10) of each treatment condition. The results do not support the hypothesis that the impact of short selling restrictions on prices decreases with experience. Both the number of cases in which the price level was higher in the presence of short sale constraints and the average price differences were similar in the first and in the second half of the experiments.

Panel B of Table 7 compares the results from the sessions with inexperienced and experienced subjects. Again, there is not much evidence that the impact of short selling restrictions on prices decreases with experience. Experienced subjects produce less overvaluation in the PA treatments but appear to produce more overvaluation than inexperienced subjects in the A-P treatments. The results in Table 7 thus suggest that the (weak) support for the overvaluation hypothesis documented earlier is not attributable to inexperienced subjects.

\section{Insert Table 7 about here}

Thus far, we have solely compared prices obtained under different treatment conditions. To obtain a more complete picture of the relation between short sale constraints and asset valuation, we augment these univariate statistics with a pooled regression analysis. The dependent variable is the (equally weighted) average price ${ }^{18}$ in each of 20 periods $^{19}$ of the 18 sessions. The price is likely to depend on the treatment and on the realization of the asset value process. For example, when $\mathrm{p}=0.8$, subjects have more precise information compared to the case where $\mathrm{p}=0.6$. We should thus expect higher prices in the $\mathrm{p}=0.8$ treatments when the true value is high and lower prices when the true value is low. To capture these effects, we included dummy variables for each treatment (except AP0 which is the base case) and interaction terms,

\footnotetext{
18 Using the digitally weighted average price or the bid-ask midpoint instead yields similar conclusions.

19 In period 14 of one session (PA60E), no transactions took place. The total number of observations in the regression is thus 359 .
} 
defined as the product of the treatment dummies and a dummy variable that equals one when the realized asset value is high.

In addition to these control variables, we included a dummy variable that equals one when short selling is prohibited (model 1). The overvaluation hypothesis predicts a positive coefficient. In an additional model (model 2), we further added two terms that interact the no short sales dummy with two dummy variables taking on the value one when $\mathrm{p}=0.6$ and $\mathrm{p}=$ 0.8 , respectively. The coefficients on these interaction terms measure whether the overvaluation is more pronounced when the degree of divergence of opinion increases. The overvaluation hypothesis predicts positive coefficients for both dummies.

\section{$\underline{\text { Insert Table } 8 \text { about here }}$}

The results are presented in Table 8 . The adjusted $\mathrm{R}^{2}$ for both models is 0.55 . The control and treatment variables thus explain more than half of the variation in prices. Many of the treatment dummies and the interactions of the treatment dummies with the asset value dummy are significant, and most of the coefficients have the expected sign. Most importantly, prices are significantly higher when short sales are prohibited. The coefficient on the no short sales dummy is 5.06 (t-statistic 2.63) in model 1 and 4.90 (t-statistic 3.21) in model 2. Thus, a short sale ban results in a price increase of approximately 5 ECU. This corresponds to $3.3 \%$ of the unconditional expected value of the asset. These results are consistent with Hypothesis 3.

The coefficients on the additional interaction terms in model 2 are far from being significant. Thus, contrary to Hypothesis 4 (but consistent with our previous results), overvaluation does not increase in the degree of divergence of opinion. We provide a tentative explanation for this result in the following section. 


\subsection{Discussion}

Our results provide partial support for Miller's (1977) overvaluation hypothesis. We do find that asset prices are higher when short sale constraints are imposed. We do not find, however, that the overvaluation increases in the degree of divergence of opinion.

The explanation we offer is rooted in the design of our experiments. We needed to endow traders with different information about the value of the asset to create divergence of opinion. At the same time, however, we had to (or at least wanted to) abide by the established principles of experiments in economics. One of these principles states that the experimenter should not lie to the experimental subjects. We therefore created a design in which subjects received noisy signals but were correctly informed about the precision of these signals. Each subject was thus aware of the quality of the information she received. As a consequence, in our experiments, the information held by the traders was fully consistent with the true processes determining the fundamental value of the asset and the private signals that the traders received.

The situation in the field may be fundamentally different. The behavioral finance literature has produced considerable evidence that traders in real world securities markets often have biased expectations, are overconfident about the precision of their information and their investment abilities and are sometimes driven by "sentiment". Investors are obviously not fully aware of these behavioral biases. Consequently, the information traders have (or believe to have) is not necessarily consistent with the true process.

Our finding that short sale constraints have an impact on asset prices even under the restrictive conditions that we imposed in our experiments is, in our opinion, a strong result. We conjecture that the consistency requirement we imposed is responsible for the absence of a relation between the degree of divergence of opinion and overvaluation. Creating experimental 
designs that do not impose such a consistency requirement is a potential avenue for future research. The design of such experiments should, however, be closely guided by empirical evidence from the field. Otherwise the danger arises that the design becomes arbitrary and produces arbitrary results.

\section{Summary and conclusion}

The overvaluation hypothesis first put forward by Miller (1977) predicts that assets will be overvalued when (a) short sale constraints and (b) differences of opinion exist. Numerous empirical studies have been conducted to test the overvaluation hypothesis. The results of these studies have not been fully conclusive, partially due to measurement problems. Neither the degree to which a stock is short sale constrained nor the degree of divergence of opinion and the true value of a stock are directly observable.

To avoid the measurement problems present in empirical studies, we used an experimental approach. In a laboratory setting, we know the fundamental value of the asset, we control the information held by the subjects (and thereby the degree of divergence of opinion) and we can impose short sale constraints under ceteris-paribus conditions. We can thus examine the impact of short selling constraints on valuation. Our design further allows variation of the degree of divergence of opinion across markets.

The results are only partially supportive of the overvaluation hypothesis. We find evidence of higher asset values in the presence of short sale constraints. We do not find, however, that overvaluation increases in the degree of divergence of opinion. We further document that trading volume is lower under short sale constraints. Finally, we find that short sale constraints have negative effects on liquidity. This result is consistent with recent empirical evidence from the 2008 short selling ban. 


\section{References}

Ackert, L., Charupat, N., Church, B., Deaves R., 2002. Bubbles in experimental asset markets: Irrational exuberance no more. Federal Reserve Bank of Atlanta Working Paper 200224, December.

Aitken, M., Frino, A., McCorry, M., Swan, P., 1998. Short sales are almost instantaneously bad news: Evidence from the Australian stock exchange. Journal of Finance 53, 2205-2223.

Asquith, P., Meulbroek, L., 1996. An empirical investigation of short interest. Working Paper, Harvard University.

Asquith, Paul, Pathak, P., Ritter, J., 2005. Short interest, institutional ownership and stock returns. Journal of Financial Economics 78, 243-276.

Au, A., Doukas, J., Onayev, Z., 2009. Daily short interest, idiosyncratic risk, and stock returns. Journal of Financial Markets 12, 290-316.

Autore, D., Billingsley, R., Kovacs, T., 2010a. The 2008 short sale ban: Liquidity, dispersion of opinions, and the cross-section of returns on U.S. financial stocks. Working Paper, June.

Autore, D., Boulton, Th., Braga-Alves, M., 2010b. Failures to deliver, short sale constraints, and stock overvaluation. Working Paper, March.

Battalio, R., Schultz, P., 2006. Options and the bubble. Journal of Finance 61, 2071-2102.

Beber, A., Pagano, M., 2009. Short selling bans and market liquidity around the world: Evidence from the 2007-09 crisis. Working Paper, November. 
Berkman, H., Dimitrov, V., Jain, P., Koch, P. Tice, S., 2009. Sell on news: difference of opinion, short-sales constraints, and returns around earnings announcements. Journal of Financial Economics 92, 376-399.

Berkman, H., Koch, P., 2008. Disagreement, short sale constraints, and speculative trading before earnings announcements. Working Paper, June.

Bhojraj, S., Bloomfield, R., Tayler, W., 2009. Margin trading, overpricing, and synchronization risk. Review of Financial Studies 22, 2059-2085.

Boehme, R., Danielsen, B., Sorescu, S., 2005. Short sale constraints, difference of opinion, and overvaluation. Journal of Financial and Quantitative Analysis 41, 455-487.

Boehmer, E., Jones, Ch., Zhang, X., 2008. Which shorts are informed? Journal of Finance 63, 491-527.

Boehmer, E., Huszar, Z., Jordan, B., 2010. The good news in short interest. Journal of Financial Economic 96, 80-97.

Boehmer, E., Jones, C., Zhang, X., 2009. Shackling short sellers: The 2008 shorting ban. Working Paper, June.

Boulton, T., Braga-Alves, M., 2010. The skinny on the 2008 naked short-sale restrictions. Journal of Financial Markets 13, 397-421.

Brent, A., Morse, D., Stice, E., 1990. Short interest: explanations and tests. Journal of Financial and Quantitative Analysis 25, 273-289.

Bris, A., Goetzmann, W., Zhu, N., 2007. Efficiency and the bear: Short sales and markets around the world. Journal of Finance 62, 1029-1079. 
Chang, E., Yu, Y., 2007. Short-sales constraints and price discovery: evidence from the Hong Kong market. Journal of Finance 62, 2097-2121.

Charoenrook, A., Daouk, H., 2005. A study of market-wide short-selling restrictions. Working Paper, January.

Cohen, L., Diether, K., Malloy, Ch., 2007. Supply and demand shifts in the shorting market. Journal of Finance 62, 2061-2096.

D'Avolio, G., 2002. The market for borrowing stock. Journal of Financial Economics 66, 271306.

Danielsen, B.R., Sorescu, S.M., 2001. Why do option introductions depress stock prices? A study of diminishing short-sale constraints. Journal of Financial and Quantitative Analysis $36,451-484$.

Dechow, P.M., Hutton, A.P., Meulbroek, L., Sloan, R.G., 2001. Short-Sellers, Fundamental analysis and stock returns. Journal of Financial Economics 61, 77-106.

Desai, H., Ramesh, K., Thiagarajan, S.R., Balachandran, B.V., 2002. An investigation of the informational role of short interest in the Nasdaq market. Journal of Finance 57, 22632287.

Diamond, D., Verrecchia, R., 1987. Constraints on short-selling and asset price adjustment to private information. Journal of Financial Economics 18, 277-311.

Diether, K., Lee, K.-H., Werner, I., 2005. Can short sellers predict returns? Daily evidence. Working Paper, Ohio State University, July.

Diether, K., Lee, K.-H., Werner, I., 2009a. Short-sale strategies and return predictability. Review of Financial Studies 22, 575-607. 
Diether, K., Lee, K.-H., Werner, I., 2009b. It's SHO time! Short-sale price sests and market quality. Journal of Finance 64, 37-73.

Diether, K., Malloy, C.J., Scherbina, A., 2002. Differences of opinion and the cross-section of stock returns. Journal of Finance 57, 2113-2141.

Diether, K., Werner, I., 2009. When constraints bind. Working Paper, July.

Dong, M., Michel, J.-S., 2008. Does investor heterogeneity lead to IPO overvaluation? Working Paper, March.

Duffie, D., Garleanu, N., Pedersen, L.H., 2002. Securities lending, shorting and pricing. Journal of Financial Economics 66, 307-339.

Figlewski, S., Webb, G.P., 1993. Options, short sales, and market completeness. Journal of Finance 48, 761-777.

Fischbacher, U., 2007. z-Tree: Zurich toolbox for ready-made economic experiments. Experimental Economics, 10, 171-178.

Francis, J, Venkatachalam, M., Zhang, Y., 2005. Do short sellers convey information about changes in fundamentals or risk? Working Paper, Duke University, September.

Gagnon, L., Witmer, J., 2010. Short Changed? The market's reaction to the short sale ban of 2008. Working Paper, March.

Gallmeyer, M., Hollifield, B., 2008. An examination of heterogeneous beliefs with a short-sale constraint in a dynamic economy. Review of Finance 12, 323-364.

Greenwood, R., 2009. Trading restrictions and stock prices. Review of Financial Studies 22, 509-539. 
Gopalan, M., 2003. Short constraints, difference of opinion and stock returns. Working Paper, Duke University.

Greiner, B., 2004. The online recruitment system ORSEE 2.0 - a guide for the organization of experiments in economics. Working Paper Series in Economics 10, University of Cologne.

Harris, L., Namvar, E., Pillips, B., 2009. Price inflation and wealth transfer during the 2008 SEC short-sale ban. Working Paper.

Haruvy, E., Noussair, Ch., 2006. The effect of short selling on bubbles and crashes in experimental spot asset markets. Journal of Finance 61, 1119-1157.

Hong, H., Stein, J., 2003. Differences of opinion, short sales constraints and market crashes. Review of Financial Studies 16, 487-525.

Jiang, D., 2005. Overconfidence, short-sale constraints, and stock valuation. Working Paper, Ohio State University, September.

Johnson, T., 2004. Forecast dispersion and the cross section of expected returns. Journal of Finance 59, 1957-1978.

Jones, C.M., Lamont, O.A., 2002. Short sale constraints and stock returns. Journal of Financial Economics 66, 207-239.

Kaplan, S., Moskowitz, T., Sensoy, B., 2010. The effects of stock lending on security prices: An experiment. Working Paper.

King, R., Smith, V., Williams, A., Van Boening, M., 1993. The robustness of bubbles and crashes in experimental stock markets. In: I. Prigogine, R. Day, and P. Chen (Eds.) Nonlinear Dynamics and Evolutionary Economics, Oxford: Oxford University Press. 
Mayhew, S., Mihov, V., 2004. Short sale constraints, overvaluation and the introduction of options. Working Paper, SEC and Texas Christian University, December.

Miller, E., 1977. Risk, uncertainty, and divergence of opinion. Journal of Finance 32, 11511168.

Nagel, S., 2005. Short sales, institutional investors and the cross-section of stock returns. Journal of Financial Economics 78, 277-309.

Ofek, E., Richardson, M., Whitelaw, R., 2004. Limited arbitrage and short sale restrictions: Evidence from the options market. Journal of Financial Economics 74, 305-342.

Phillips, B., 2011. Options, short-sale constraints and market efficiency: A new perspective. Journal of Banking and Finance 35, 430-442.

Reed, A., 2007. Costly short-selling and stock price adjustment to earnings announcements. Working Paper, University of North Carolina, July.

Scheinkman, J., Wie, X., 2003. Overconfidence and speculative bubbles. Journal of Political Economy 111, 1183-1219.

Smith, V., Suchanek, G., Williams, A., 1988. Bubbles, crashes, and endogenous expectations in experimental spot asset markets. Econometrica 56, 1119-1151. 


\section{Table 1: Parameter choice}

The table shows the parameters used in the individual experimental treatments. It further shows the expected value of the asset conditional on the signal and the expected number of traders with a correct and an incorrect signal. The full information benchmark is the expected value of the asset conditional on all 10 signals and under the assumption that the numbers of correct and incorrect signals are equal to their expected values. The last line shows the measure of divergence of opinion, $\theta$.

\begin{tabular}{|c|c|c|c|c|c|c|}
\hline & \multicolumn{2}{|c|}{$\mathrm{p}=0$ (benchmark) } & \multicolumn{2}{|c|}{$\mathrm{p}=0.6$} & \multicolumn{2}{|c|}{$\mathrm{p}=0.8$} \\
\hline & \multicolumn{2}{|c|}{ asset value } & \multicolumn{2}{|c|}{ asset value } & \multicolumn{2}{|c|}{ asset value } \\
\hline & high & low & high & low & high & low \\
\hline asset value & 200 & 100 & 200 & 100 & 200 & 100 \\
\hline $\begin{array}{l}\text { cond. expectation of } \\
\text { trader with signal } h\end{array}$ & na & na & 160 & 160 & 180 & 180 \\
\hline $\begin{array}{l}\text { expected number of } \\
\text { traders with signal } h\end{array}$ & na & na & 6 & 4 & 8 & 2 \\
\hline $\begin{array}{l}\text { cond. expectation of } \\
\text { trader with signal } 1\end{array}$ & na & na & 140 & 140 & 120 & 120 \\
\hline $\begin{array}{l}\text { expected number of } \\
\text { traders with signal } 1\end{array}$ & na & na & 4 & 6 & 2 & 8 \\
\hline $\begin{array}{l}\text { full information bench- } \\
\text { mark }\end{array}$ & 150 & 150 & 169.23 & 130.77 & 199.98 & 100.02 \\
\hline $\begin{array}{l}\text { measure of divergence of } \\
\text { opinion }(\theta)\end{array}$ & \multicolumn{2}{|c|}{0} & \multicolumn{2}{|c|}{0.0096} & \multicolumn{2}{|c|}{0.0576} \\
\hline
\end{tabular}




\section{Table 2: Treatment summary}

The table describes the treatments and shows the number of sessions that were conducted with each treatment condition.

\begin{tabular}{|c|c|c|}
\hline \multirow[b]{2}{*}{ Signal precision } & \multicolumn{2}{|c|}{ sequence of treatments } \\
\hline & $\begin{array}{l}\text { short selling prohibited - short sell- } \\
\text { ing allowed (PA) }\end{array}$ & $\begin{array}{l}\text { short selling allowed - short selling } \\
\text { prohibited (AP) }\end{array}$ \\
\hline no signals (benchmark case) & PA0 - session 1 & AP0 session 10 \\
\hline$p=0.6$ & $\begin{array}{l}\text { PA60 - sessions 2-4 } \\
\text { PA60E - session } 5\end{array}$ & $\begin{array}{l}\text { AP60 sessions 11-13 } \\
\text { AP60E - session } 14\end{array}$ \\
\hline $\mathrm{p}=0.8$ & $\begin{array}{l}\text { PA80 - sessions 6-8 } \\
\text { PA80E - session } 9\end{array}$ & $\begin{array}{l}\text { AP80 sessions 15-17 } \\
\text { AP80E - session } 18\end{array}$ \\
\hline
\end{tabular}




\section{Table 3: Short selling activity}

The table shows the number of short sales in periods without restrictions. Column 3 displays the absolute number of sales, column 4 the absolute number of short sales, and column 5 reports short sales as a percentage of total sales. Column 6 aggregates these shares for the benchmark treatment and the two divergence of opinion treatments.

\begin{tabular}{lccccc}
$\begin{array}{l}\text { Divergence } \\
\text { of opinion }\end{array}$ & $\begin{array}{c}\text { Order of } \\
\text { treatments }\end{array}$ & \#sales & $\begin{array}{c}\text { \#short } \\
\text { sales }\end{array}$ & \multicolumn{2}{c}{$\%$ short sales } \\
\hline Benchmark & P-A & 214 & 82 & $38.32 \%$ & $31.39 \%$ \\
$\mathrm{p}=0.6$ & A-P & 95 & 15 & $15.79 \%$ & \\
& P-A & 507 & 148 & $29.19 \%$ & $20.61 \%$ \\
$\mathrm{p}=0.8$ & A-P & 814 & 128 & $15.72 \%$ & \\
\hline total & P-A & 481 & 181 & $37.63 \%$ & \multirow{2}{*}{ A-P } \\
\hline
\end{tabular}




\section{Table 4: Trading volume}

The table shows the mean and the median trading volume per period for the different treatment conditions. Columns 5 and 8 report the t-statistics and the z-statistics for a test of the null hypothesis of equal means and medians, respectively. The last line shows results pooled over all treatment conditions.

\begin{tabular}{lccccccc}
$\begin{array}{c}\text { Diver- } \\
\text { gence of } \\
\text { opinion }\end{array}$ & $\begin{array}{c}\text { Order of } \\
\text { treatments }\end{array}$ & \multicolumn{2}{c}{ mean volume per period } & \multicolumn{3}{c}{ median volume per period } \\
short sales & short sales & t-statistic & short sales & short sales & z-statistic \\
allowed & prohibited & \\
\hline $\begin{array}{l}\text { Bench- } \\
\text { mark }\end{array}$ & P-A & 27.10 & 32.10 & -0.96 & 26.50 & 29.00 & 0.99 \\
\multirow{2}{*}{$\mathrm{p}=0.6$} & A-P & 10.60 & 8.00 & $2.28^{*}$ & 11.00 & 8.00 & $2.02^{*}$ \\
& P-A & 13.67 & 12.07 & 0.84 & 13.50 & 9.00 & 1.57 \\
$\mathrm{p}=0.8$ & A-P & 23.60 & 12.27 & $4.25^{* *}$ & 18.50 & 11.60 & $3.89^{* * *}$ \\
& P-A & 14.25 & 11.12 & $1.99^{*}$ & 13.00 & 11.00 & 1.41 \\
& A-P & 23.42 & 9.42 & $4.20^{* *}$ & 15.50 & 8.00 & $3.94^{* *}$ \\
\hline
\end{tabular}

Note: ${ }^{* *}$ denotes significance on a $1 \%$ level, and ${ }^{*}$ denotes significance at the $5 \%$ level. 


\section{Table 5: Liquidity}

The table shows average bid-ask spreads for the different treatment conditions. Panel A shows mean quoted spreads, Panel B shows mean effective spreads. The results are differentiated with respect to the degree of divergence of opinion, the order of treatments (P-A and A-P) and the short selling condition (allowed and prohibited). Columns 9-11 show the t-statistics for the null hypothesis of equal means. The t-statistic in columns 7-11 relate to a comparison of the prices in columns 1 and 4 ( 2 and 5; 3 and 6,1 and 6, and 2 and 5).

\section{Panel A: Mean Quoted Spreads}

\begin{tabular}{lccccccccccc}
$\begin{array}{c}\text { Divergence } \\
\text { of opinion }\end{array}$ & \multicolumn{3}{c}{ short sales allowed } & \multicolumn{3}{c}{ short sales prohibited } & \multicolumn{4}{c}{ t-statistics } \\
& P-A & A-P & pooled & P-A & A-P & pooled & P-A & A-P & pooled & $1^{\text {st }}$ half & $2^{\text {nd }}$ half \\
\hline Benchmark & 5.90 & 17.62 & 11.76 & 47.21 & 11.67 & 29.44 & $8.81^{* *}$ & $-3.79^{* *}$ & $3.59^{* *}$ & $6.37^{* *}$ & $3.42^{* *}$ \\
$\mathrm{p}=0.6$ & 25.24 & 41.09 & 33.07 & 37.10 & 32.40 & 34.75 & $5.48^{* *}$ & -1.62 & 0.56 & -0.86 & $2.20^{*}$ \\
$\mathrm{p}=0.8$ & 23.58 & 33.69 & 28.64 & 36.11 & 38.47 & 37.29 & $3.28^{* *}$ & 1.26 & $3.17^{* *}$ & 0.74 & $3.49^{* *}$ \\
\hline
\end{tabular}

\section{Panel B: Mean Effective Spreads}

\begin{tabular}{lccccccccccc}
$\begin{array}{c}\text { Divergence } \\
\text { of opinion }\end{array}$ & \multicolumn{3}{c}{ short sales allowed } & \multicolumn{3}{c}{ short sales prohibited } & \multicolumn{4}{c}{ t-statistics } \\
& P-A & A-P & pooled & P-A & A-P & pooled & P-A & A-P & pooled & $1^{\text {st }}$ half & $2^{\text {nd }}$ half \\
\hline Benchmark & 4.17 & 10.94 & 7.55 & 38.49 & 5.42 & 21.95 & $6.59^{* *}$ & $-3.45^{* *}$ & $3.07^{* *}$ & $5.16^{* *}$ & 1.11 \\
$\mathrm{p}=0.6$ & 15.20 & 36.62 & 26.05 & 25.42 & 23.59 & 24.51 & $4.39^{* *}$ & $-2.56^{*}$ & -0.51 & $-2.35^{*}$ & $2.85^{* *}$ \\
$\mathrm{p}=0.8$ & 22.27 & 25.45 & 23.86 & 27.62 & 25.75 & 26.70 & 1.41 & 0.89 & 1.12 & 0.74 & 0.83 \\
\hline
\end{tabular}

Note: ${ }^{* *}$ denotes significance at the $1 \%$ level, and ${ }^{*}$ denotes significance at the $5 \%$ level. 


\section{Table 6: Price Levels}

The table shows the mean price per period for the different treatment conditions. We report separate results for periods with low and high asset values, respectively (no such distinction is made in the benchmark treatment because there traders did not receive signals about the asset value). Columns 3-5 (6-8) report the prices for those periods where short sales were allowed (prohibited). We provide separate results for those sessions were the order of treatments was P-A and A-P, respectively, as well as aggregated results. Columns 9-11 show the t-statistics for the null hypothesis of equal means. The t-statistics in column $9(10 ; 11)$ relate to a comparison of the prices in columns 3 and 6 (4 and 7; 5 and 8).

\section{Panel A: Mean price, equally weighted}

\begin{tabular}{|c|c|c|c|c|c|c|c|c|c|c|}
\hline \multirow{2}{*}{$\begin{array}{l}\text { Diver- } \\
\text { gence of } \\
\text { opinion }\end{array}$} & \multirow{2}{*}{$\begin{array}{l}\text { Asset } \\
\text { value }\end{array}$} & \multicolumn{3}{|c|}{ short sales allowed } & \multicolumn{3}{|c|}{ short sales prohibited } & \multicolumn{3}{|c|}{ t-statistic } \\
\hline & & P-A & A-P & all & $\mathrm{P}-\mathrm{A}$ & $\mathrm{A}-\mathrm{P}$ & all & $\mathrm{P}-\mathrm{A}$ & A-P & all \\
\hline \multicolumn{2}{|c|}{ Benchmark } & 120.03 & 135.87 & 127.95 & 129.67 & 136.99 & 133.33 & $3.49^{* *}$ & 0.94 & $2.17^{*}$ \\
\hline \multirow{2}{*}{$\mathrm{p}=0.6$} & 100 & 144.10 & 138.73 & 141.42 & 158.64 & 147.96 & 152.34 & $2.82^{* *}$ & $2.22^{*}$ & $3.27^{* *}$ \\
\hline & 200 & 156.25 & 148.67 & 152.04 & 157.84 & 146.27 & 153.04 & 0.36 & -0.36 & 0.29 \\
\hline \multirow{2}{*}{$\mathrm{p}=0.8$} & 100 & 122.97 & 127.92 & 126.72 & 138.61 & 129.70 & 133.99 & 1.77 & 0.17 & 1.32 \\
\hline & 200 & 186.60 & 169.06 & 176.94 & 182.20 & 175.00 & 178.75 & -0.87 & 0.90 & 0.42 \\
\hline
\end{tabular}

\section{Panel B: Mean price, digitally weighted}

\begin{tabular}{|c|c|c|c|c|c|c|c|c|c|c|}
\hline \multirow{2}{*}{$\begin{array}{l}\text { Diver- } \\
\text { gence of } \\
\text { opinion }\end{array}$} & \multirow{2}{*}{$\begin{array}{l}\text { Asset } \\
\text { value }\end{array}$} & \multicolumn{3}{|c|}{ short sales allowed } & \multicolumn{3}{|c|}{ short sales prohibited } & \multicolumn{3}{|c|}{ t-statistic } \\
\hline & & P-A & A-P & all & P-A & A-P & all & P-A & A-P & all \\
\hline \multicolumn{2}{|c|}{ Benchmark } & 119.83 & 136.17 & 128.00 & 129.68 & 136.95 & 133.32 & $3.29^{* *}$ & 0.64 & $2.05^{*}$ \\
\hline \multirow{2}{*}{$p=0.6$} & 100 & 143.68 & 137.67 & 140.68 & 159.59 & 147.51 & 152.47 & $2.85^{* *}$ & $2.19^{*}$ & $3.26^{* *}$ \\
\hline & 200 & 146.93 & 150.49 & 148.71 & 157.49 & 147.47 & 153.33 & 1.21 & -0.54 & 0.85 \\
\hline \multirow{2}{*}{$\mathrm{p}=0.8$} & 100 & 120.37 & 126.53 & 122.95 & 137.51 & 129.21 & 133.12 & 1.77 & 0.25 & 1.44 \\
\hline & 200 & 188.09 & 170.04 & 178.14 & 184.53 & 175.82 & 180.36 & -0.70 & 0.85 & 0.50 \\
\hline
\end{tabular}

\section{Panel C: Bid-ask midpoint}

\begin{tabular}{cccccccccccc}
$\begin{array}{c}\text { Diver- } \\
\text { gence of } \\
\text { opinion }\end{array}$ & $\begin{array}{c}\text { Asset } \\
\text { value }\end{array}$ & \multicolumn{2}{c}{ short sales allowed } & \multicolumn{2}{c}{ short sales prohibited } & \multicolumn{3}{c}{ t-statistic } \\
\hline \multicolumn{2}{c}{ Benchmark } & 119.86 & 135.26 & 127.56 & 133.17 & 136.43 & 134.80 & $7.03^{* *}$ & 0.90 & $3.41^{* *}$ \\
& 100 & 142.55 & 143.15 & 142.85 & 152.87 & 146.97 & 149.39 & $2.35^{* *}$ & 1.07 & $2.36^{*}$ \\
$\mathrm{p}=0.6$ & 200 & 154.38 & 149.22 & 151.80 & 154.92 & 149.49 & 152.67 & 0.14 & 0.06 & 0.30 \\
& 100 & 119.81 & 127.68 & 123.11 & 134.03 & 132.67 & 133.31 & 1.88 & 0.64 & 1.90 \\
$\mathrm{p}=0.8$ & 200 & 180.21 & 166.35 & 172.57 & 172.09 & 170.03 & 171.11 & -1.70 & 0.80 & -0.43 \\
\hline
\end{tabular}

Note: ${ }^{* *}$ denotes significance on a $1 \%$ level, and ${ }^{*}$ denotes significance at the $5 \%$ level. 


\section{Table 7: Learning}

Panel A shows average prices for the first half (periods 1-5) and the second half (periods 6-10) of the different treatment conditions. The results are differentiated with respect to the degree of divergence of opinion $(\mathrm{p}=0.6$ and $\mathrm{p}=0.8$ ), the realization of the asset value process (with the exception of the benchmark case), the order of treatments (P-A and A-P) and the short selling condition (allowed and prohibited). Panel B compares the results from the sessions with inexperienced and experienced subjects. There are no results for the benchmark treatment because there was no session with the benchmark treatment and experienced subjects. The structure of Panel B is similar to Panel A.

Panel A: First half versus second half

\begin{tabular}{cccccccccc}
$\begin{array}{c}\text { Diver- } \\
\text { gence of } \\
\text { opinion }\end{array}$ & $\begin{array}{c}\text { Asset } \\
\text { value }\end{array}$ & \multicolumn{4}{c}{ short sales allowed } & \multicolumn{3}{c}{ short sales prohibited } \\
& & \multicolumn{2}{c}{ P-A } & \multicolumn{2}{c}{ A-P } & \multicolumn{2}{c}{ P-A } & \multicolumn{2}{c}{ A-P } \\
\hline \multicolumn{2}{c}{ benchmark } & 124.88 & 115.19 & 137.12 & 134.63 & 129.85 & 129.50 & 136.87 & 137.12 \\
$\mathrm{p}=0.6$ & 100 & 146.08 & 142.73 & 137.80 & 139.51 & 151.23 & 174.93 & 148.18 & 147.72 \\
& 200 & 154.92 & 158.15 & 145.14 & 157.72 & 158.68 & 157.33 & 142.25 & 149.84 \\
$\mathrm{p}=0.8$ & 100 & 126.67 & 118.34 & 129.05 & 126.69 & 145.82 & 131.40 & 122.36 & 144.38 \\
& 200 & 186.64 & 186.57 & 157.50 & 179.81 & 182.65 & 181.75 & 172.64 & 176.34 \\
\hline
\end{tabular}

Panel B: Inexperienced versus experienced subjects

\begin{tabular}{cccccccccc}
$\begin{array}{c}\text { Diver- } \\
\text { gence of } \\
\text { opinion }\end{array}$ & $\begin{array}{c}\text { Asset } \\
\text { value }\end{array}$ & \multicolumn{3}{c}{ short sales allowed } & \multicolumn{3}{c}{ short sales prohibited } \\
& & inexp. & exp. & inexp. & exp. & inexp. & exp. & inexp. & exp. \\
\hline \multirow{2}{*}{$\mathrm{p}=0.6$} & 100 & 145.35 & 141.92 & 136.13 & 147.57 & 160.23 & 147.50 & 143.41 & 158.36 \\
& 200 & 156.33 & 155.00 & 143.36 & 160.30 & 159.75 & 154.01 & 143.45 & 159.41 \\
& 100 & 116.76 & 144.70 & 134.90 & 104.65 & 148.62 & 125.73 & 133.04 & 117.99 \\
$\mathrm{p}=0.8$ & 200 & 188.35 & 181.94 & 173.46 & 156.52 & 182.32 & 181.35 & 178.13 & 166.63 \\
\hline
\end{tabular}




\section{Table 8: Regression results}

The table shows the results of OLS regressions. The dependent variable is the equally-weighted mean price of each period. We include control variables for the different treatment conditions and interactions between these control variables and a dummy that is equal to 1 whenever the asset value is high (200). In model 1, we include a dummy variable that equals 1 when short selling is prohibited. In model 2 , we further include interactions between the short selling dummy and dummy variables that equal 1 in those sessions where $\mathrm{p}=0.6$ and $\mathrm{p}=0.8$ (denoted $\operatorname{div} 60$ and div 80), respectively. The number of observations is 359 (18 sessions, each with 20 periods; in one period no transaction took place). $\mathrm{t}$-values are based on heteroscedasticity-consistent standard errors.

\begin{tabular}{lclrl} 
& \multicolumn{2}{c}{ Model 1 } & \multicolumn{2}{c}{ Model 2 } \\
& coefficient & t-value & coefficient & t-value \\
\hline constant & 134.47 & $(69.51)^{* *}$ & 134.58 & $(72.16)^{* *}$ \\
AP60 & 2.73 & $(1.04)$ & 2.08 & $(0.72)$ \\
AP80 & -3.61 & $(0.57)$ & -3.12 & $(0.47)$ \\
AP60E & 16.43 & $(3.77)^{* *}$ & 15.68 & $(3.28)^{* *}$ \\
AP80E & -25.09 & $(7.35)^{* *}$ & -24.62 & $(5.87)^{* *}$ \\
PA0 & -9.33 & $(4.03)^{* *}$ & -9.35 & $(3.95)^{* *}$ \\
PA60 & 15.78 & $(4.49)^{* *}$ & 15.12 & $(4.00)^{* *}$ \\
PA80 & -7.23 & $(1.48)$ & -6.94 & $(1.28)$ \\
PA60E & 7.55 & $(1.65)$ & 7.22 & $(0.42)$ \\
PA80E & -5.07 & $(0.51)$ & -4.52 & $(0.66)$ \\
Value200 & -1.04 & $(0.63)$ & -1.09 & $(1.26)$ \\
AP60*Value200 & 4.62 & $(1.25)$ & 4.63 & $(5.75)^{* *}$ \\
AP80*Value200 & 43.46 & $(5.76)^{* *}$ & 43.37 & $(1.26)$ \\
AP60E*Value200 & 8.20 & $(1.23)$ & 8.48 & $(8.52)^{* *}$ \\
AP80E*Value200 & 50.51 & $(8.57)^{* *}$ & 50.45 & $(1.72)$ \\
PA0*Value200 & -5.21 & $(1.75)$ & -5.18 & $(10.14)^{* *}$ \\
PA60*Value200 & 6.29 & $(1.46)$ & 6.34 & $(1.14)$ \\
PA80*Value200 & 55.85 & $(10.20)^{* *}$ & 56.08 & $(3.69)^{* *}$ \\
PA60E*Value200 & 8.64 & $(1.23)$ & 7.92 & $(3.21)^{* *}$ \\
PA80E*Value200 & 51.69 & $(3.72)^{* *}$ & 51.43 & $(0.47)$ \\
no short sales & 5.06 & $(2.63)^{* *}$ & 4.90 & $(0.22)$ \\
no short sales*div60 & & & 1.27 & \\
no short sales*div80 & & & -0.86 & \\
\hline adj. R ${ }^{2}$ & & & & 0.55 \\
\hline
\end{tabular}

$*$ significant at $5 \% ; * *$ significant at $1 \%$ 


\section{CFS Working Paper Series:}

No.

2011/04

André Betzer

Jasmin Gider

Daniel Metzger

Erik Theissen

2011/03 Joachim Grammig

Eric Theissen

2011/02 Jördis Hengelbrock

Eric Theissen

Christian Westheide

2011/01 Mathias Hoffmann

Michael U. Krause

Thomas Laubach

2010/26 Ester Faia

2010/25 Ignazio Angeloni

Ester Faia

Roland Winkler

2010/24 Roman KräussI

Andre Lucas

Arjen Siegmann

2010/23 Carmen Lee

Roman Kräussl

Andre Lucas

Leo Paas

2010/22 Steffen Juranek Uwe Walz

2010/20 Mahmoud Botshekan Roman KraeussI Andre Lucas
Title

Strategic Trading and Trade Reporting by Corporate Insiders

Is BEST Really Better? Internalization of Orders in an Open Limit Order Book

Market Response to Investor Sentiment

Long-run Growth Expectations and "Global Imbalances"

Credit Risk Transfers and the Macroeconomy

Exit Strategies

Risk Aversion under Preference Uncertainty

Why Do Investors Sell Losers? How

Adaptation to Losses Affects Future

Capitulation Decisions

Vertical Integration, Competition, and Financial Exchanges: Is there Grain in the Silo?

Cash Flow and Discount Rate Risk in Up and Down Markets: What Is Actually Priced?

Copies of working papers can be downloaded at http://www.ifk-cfs.de 